\title{
Genetic Diversity in Aus Rice Genotypes using ILP Markers
}

\author{
M A Siddique ${ }^{1 *}$, M Khalequzzaman ${ }^{1}$, M Z Islam ${ }^{1}$, E S M H Rashid ${ }^{1}$, \\ M H K Baktiar ${ }^{1}$ and M A Z Chowdhury ${ }^{2}$
}

\begin{abstract}
Assessment of genetic diversity is essential for germplasm characterization, utilization and conservation. Genetic diversity of 31 Aus rice genotypes of Bangladesh was assessed using 11 ILP (intron length polymorphism) markers. A total of 28 alleles were detected and the number of alleles per locus varied from 2 (RI01779, RI05751, RI05304, RI03205, RI00299, RI05407) to 4 (RI05559). The PIC values ranged from 0.06 (RI05407) to 0.57 (RI05559) with an average of 0.33 . PIC value revealed that RI05559 was the best ILP markers for the studied 31 Aus rice genotypes. The dendrogram from unweighted pair-group method with arithmetic average clustering classified the genotypes into five groups at a coefficient of 0.57 . Two dimensional graphical views of Principal Coordinate Analysis (PCoA) revealed that the genotypes Kuchmuch, Kalo dhan, Aus dhan, Sadey aus, Chaina and Dighi bawalia were found far away from the centroid of the cluster and can be seslected as parents for further breeding programmes. Parangi and V3, Adubali and H1-2, Begunbichi and Hashikalmi had closest distance (0.000) in the distance matrix might have same genetic background. This information will be useful for the selection of genetically diversed parents and assist in trait development using genotypes in rice breeding programmes in future. The results provided some useful implications for establishment of sovereignty of Bangladeshi rice gene pool. It was also suggested that ILP markers could be very useful for the genetic study and breeding in rice.
\end{abstract}

Key words: Aus rice genotypes, genetic diversity, cluster analysis, allele scoring, intron-length polymorphism

\section{INTRODUCTION}

Rice (Oryza sativa L.) is an important cereal crop grown exclusively for human consumption that is the staple food for about $50 \%$ of the global population (Garris et al., 2005; Ramkumar et al., 2010).

Rice genetic resource is the primary material for rice breeding and makes a concrete contribution to global wealth creation and food security (Zhang et al., 2011). Rice genotypes contain greater genetic diversity than elite cultivars (Londo et al., 2006). However, Bangladesh had abundant rice germplasm from time immemorial. But, local and traditional genotypes of rice are now replacing with the modern varieties (MVs) in Bangladesh. Besides, various interventions of rice habitat are occurring due to over population. Therefore, rice genotypes need to exploit in hybridization programme for maintaining total rice gene diversity.

Exploring diversity in the landrace collection and characterization is very essential for identifying new genes and further improvement of the germplasm (Thomson et al., 2007). In Bangladesh, variety identification and diversity analysis have been done mostly through morphological descriptors. Due to stage specific expression of characters and influence of environment; morphological diversity estimates are less reliable. Moreover, at times there may be little morphological diversity among cultivars with related pedigrees. Uses of molecular markers are considered best for analysis of

${ }^{1}$ Genetic Resources and Seed Division, BRRI, Gazipur and ${ }^{2}$ Member Director (Crops), BARC, Dhaka. *Corresponding author's E-mail: mabs198401@yahoo.com 
genetic diversity and varietal identification since there is no effect of development stage, environment or management practices. Availability of a large number of polymorphic markers enables precise classification of the cultivars and germplasm collections.

Presently, various molecular marker techniques are available in helping various purposes in different crops. In rice, the commonly used techniques for diversity evaluation include: restriction fragment length polymorphism (RFLP) (Sun et al., 2001), amplified fragment length polymorphism (AFLP) (Bao et al., 2006), random amplified polymorphic DNA (RAPD) (Rabbani et al., 1998), simple sequence repeat (SSR) (Salgotra et al., 2015), and single nucleotide polymorphism (SNP) (Chen et al., 2011).

Recently, a new type molecular marker system termed intron length polymorphism (ILP) has been developed in rice by comparing the draft genomic sequences of indica cultivar 93-11 and japonica cultivar Nipponbare (Wang et al., 2005). ILP is a codominant marker and can be conveniently detected by polymerase chain reaction (PCR) with a pair of primers designed on flanking exons. ILPs are comparable among different species (Wang et al., 2005) because the exon-intron structures of genes are highly conservative across species (Zhao et al., 2009). ILPs are rich in the two cultivated subspecies in rice. Currently, there are limited reports on the use of ILP markers for the assessment of genetic diversity or related research in rice (Xu et al., 2009; Zhao et al., 2009). The present study aimed to investigate the genetic diversity of 31 Aus rice genotypes of Bangladesh using ILP markers.

\section{MATERIAL AND METHODS}

\section{Rice materials}

Thirty-one Aus rice genotypes (Table 1) were studied in the Molecular Laboratory of Genetic Resources and Seed Division of BRRI during
Table 1. List of Aus rice genotypes with place of collections.

\begin{tabular}{lccc}
\hline Designation & $\begin{array}{c}\text { Collection } \\
\text { district }\end{array}$ & Designation & $\begin{array}{c}\text { Collection } \\
\text { district }\end{array}$ \\
\hline Begunbichi & Kushtia & Raitul & Barguna \\
Hashikalmi & Kushtia & Kuchmuch & Barguna \\
Kalodhan & Kushtia & Puitraaijang & Barguna \\
Aus dhan & Kushtia & Boula & Barguna \\
Dighabawalia & Kushtia & Chaina & Barguna \\
Hanuman jata & Kushtia & Saithsail & Barguna \\
Itcrie & Meherpur & Sadeyaus & Barguna \\
V-2 & Meherpur & Mallika & Barguna \\
V-3 & Meherpur & Aduballi & Barguna \\
V-4 & Meherpur & Bardhanaus & Barguna \\
Parangi & Rajbari & Kaloaus & Barguna \\
Sandamioni & Rajbari & Bardhanaus & Barguna \\
Jaymori & Rajbari & H-171 & Barguna \\
Kalohizli & Rajbari & H-12 & Barguna \\
Minikit & Barguna & Kadidet & Barguna \\
Parangi & Barguna & -- & - \\
\hline
\end{tabular}

2016 for diversity analysis. Five gram seeds from each of the entry were first germinated and then sown in the earthen pots.

\section{ILP Markers}

Eleven ILP markers (synthesized by Beijing Sunbiotech Co., Ltd., China) were used for diversity analysis.

\section{Genomic DNA isolation and PCR amplification}

DNA was extracted from young leaves of 14-day-old plants following the Miniscale method (Zheng et al., 1995). The total PCR reaction volume was $10 \mu \mathrm{L}$, composed of $3.0 \mu \mathrm{L}$ genomic DNA, $1.0 \mu \mathrm{L}$ of $10 \times$ PCR buffer $\left(\mathrm{MgCl}_{2}\right.$ free), $1.35 \mu \mathrm{L}$ of $25 \mathrm{mmol} / \mathrm{L}$ $\mathrm{MgCl}_{2}, 0.2 \mu \mathrm{L}$ of $10 \mathrm{mmol} / \mathrm{L}$ dNTPs, 0.5 $\mu \mathrm{L}$ of $10 \mu \mathrm{mol} / \mathrm{L}$ forward and reverse primers, $0.02 \mu \mathrm{L}$ of $5 \mathrm{U} / \mu \mathrm{L}$ Taq DNA polymerase and $3.43 \mu \mathrm{L}$ sterile deionized water. The temperature profile was an initial denaturation step for $5 \mathrm{~min}$ at $94^{\circ} \mathrm{C}$, followed by 35 cycles of denaturation 
$\left(94^{\circ} \mathrm{C}\right)$ for $45 \mathrm{~s}$, annealing $\left(55^{\circ} \mathrm{C}\right.$ or $\left.61^{\circ} \mathrm{C}\right)$ for $45 \mathrm{~s}$ and primer elongation $\left(72^{\circ} \mathrm{C}\right)$ for 1.3 min and then a final extension at $72^{\circ} \mathrm{C}$ for $7 \mathrm{~min}$.

\section{Electrophoresis and visualization of amplified products}

The $10 \mu \mathrm{L}$ of PCR product with $2 \mu \mathrm{L}$ of a loading dye was analyzed using $8 \%$ polyacrylamide gel electrophoresis in $1 \times$ TBE buffer at $75 \mathrm{~V}$ for about 2.0-2.5 $\mathrm{h}$ depending upon the allele size. The gels were stained with ethidium bromide solution $(0.5 \mathrm{mg} / \mathrm{mL})$ for $25 \mathrm{~min}$ and exposed to UV light using the molecular imager gel documentation unit (XR System, Uvitec Cambridge, France) for visualization.

\section{Allele scoring and data analysis}

The size of the band for each marker was scored by Alpha-EaseFC 4.0 software. The summary statistics, including the number of alleles, major allele size and frequency, gene diversity and polymorphism information content (PIC) value, were determined using PowerMarker version 3.25 (Liu and Muse, 2005). For the unrooted phylogenic tree, genetic distance was calculated using the "C.S. Chord 1967" distance (Cavalli-Sfoza and Edwards, 1967) followed by phylogeny reconstruction using neighbour-joining as implemented in PowerMarker with tree viewed using Tree view (Page, 1996). The allele frequency data from PowerMarker was used to export the data in binary format (allele presence $=$ " 1 " and allele absence $=$ " 0 ") for analysis with NTSYSpc version 2.2 (Rohlf, 2002). A similarity matrix was also calculated with the Simqual subprogramme using the Dice coefficient followed by cluster analysis with the SAHN subprogramme using the UPGMA (Unweighted pair group method using arithmetic average) clustering method as implemented in NTSYS-pc. The similarity matrix was also used for principal coordinate analysis (PCoA) with the DCenter, Eigen, Output, and MXPlot subprogrammes in NTSYS-pc.

\section{RESULTS AND DISCUSSIONS}

\section{Overall ILP diversity}

Eleven ILP markers (Table 2) identified 28 alleles with an average of 2.55 per locus. The number of alleles per primer varied from two (RI01779, RI05751, RI05304, RI03205, RI00299, RI05407) to four (RI05559). None of the markers amplified a unique locus. The PIC values for polymorphic ILP markers ranged from 0.06 (RI05407) to 0.57 (RI05559) with an average of 0.33 . PIC value revealed that RI05559 was considered as the best ILP markers for 31 Aus rice genotypes. Figure 1 shows the DNA profiles of 31 Aus rice with ILP Marker RI05559.

\section{Genetic distance-based analysis}

The UPGMA clusters identically showed that the 31 genotypes were grouped into five major clusters at a coefficient of 0.57 and the similarity coefficient value ranged from 0.38 to 100 (Fig. 2).

\section{Principal coordinate analysis}

The two dimensional graphical view of principal coordinate analysis (PCoA) showed the spatial distribution of the genotypes along the two principal axes. The genotypes Kuchmuch, Kalodhan, Sadeyaus, Chaina, Aus dhan and Dighi bawalia were found far away from centroid of the cluster and the rest of the genotypes were placed more or less around the centroid (Fig. 3). The results indicated that the genotypes placed far away from the centroid were more genetically diverse, while the genotypes placed near around the centroid possessed more or less similar genetic background. However, centroid could be defined as the vector representing the middle point of the cluster, which contained at least one number for each variable. The connecting lines between each genotype and the centroid represented eigan vectors for the respective genotypes.

Genetic diversity study is of prime importance in conservation of endangered species and utilization of appropriate plant resources from diverse germplasm. Successful breeding for crop development programmes 
Table 2. Allele number, size and frequency, genetic diversity and PIC among 31 Aus rice genotypes for 11 ILP markers.

\begin{tabular}{|c|c|c|c|c|c|c|c|c|}
\hline ILP Marker & $\begin{array}{c}\text { Chro. } \\
\text { no. }\end{array}$ & $\begin{array}{c}\text { Position } \\
(\mathrm{cM})^{*}\end{array}$ & Allele no. & Range (bp) & Size (bp) & Freq (\%) & $\begin{array}{c}\text { Gene } \\
\text { diversity }\end{array}$ & PIC \\
\hline RI05333 & 2 & - & 3 & $269-284$ & 284 & 70.97 & 0.43 & 0.36 \\
\hline RI01779 & 3 & - & 2 & $278-282$ & 282 & 64.52 & 0.46 & 0.35 \\
\hline RI05751 & 4 & - & 2 & $246-274$ & 274 & 51.61 & 0.50 & 0.37 \\
\hline RI05304 & 7 & - & 2 & $226-238$ & 238 & 87.10 & 0.22 & 0.20 \\
\hline RI03205 & 8 & - & 2 & $115-128$ & 128 & 90.32 & 0.17 & 0.16 \\
\hline RI03489 & 8 & - & 3 & $278-294$ & 294 & 74.19 & 0.41 & 0.37 \\
\hline RI00299 & 10 & - & 2 & $258-280$ & 280 & 67.74 & 0.44 & 0.34 \\
\hline RI02102 & 11 & - & 3 & $293-310$ & 293 & 51.61 & 0.53 & 0.42 \\
\hline RI05373 & 12 & - & 3 & $337-362$ & 337 & 64.52 & 0.51 & 0.44 \\
\hline RI05407 & 12 & - & 2 & $202-209$ & 209 & 96.67 & 0.09 & 0.06 \\
\hline RI05559 & 12 & - & 4 & $185-216$ & 216 & 45.16 & 0.64 & 0.57 \\
\hline Total & & & 28 & & & 764.41 & 4.38 & 3.66 \\
\hline Mean & & & 2.55 & & & 69.491 & 0.40 & 0.33 \\
\hline
\end{tabular}

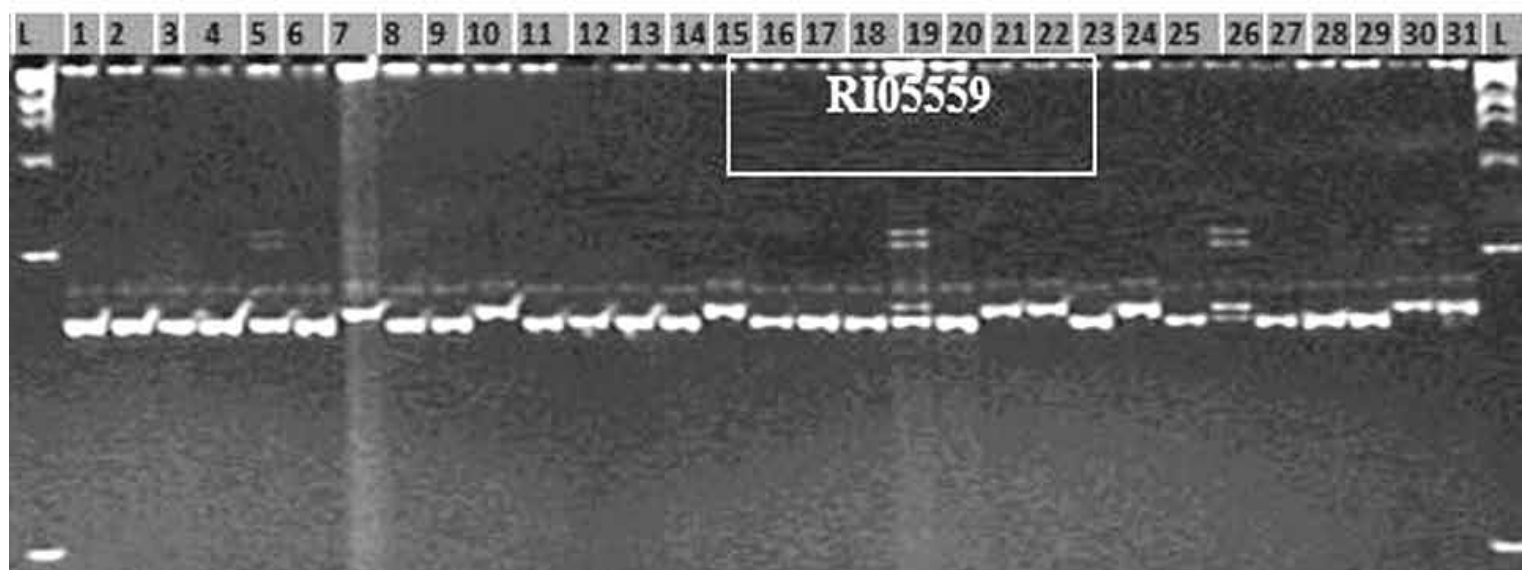

Fig. 1. DNA profile of 31 Aus rice genotypes with ILP marker RI05559.

Legend: 1=Begun bichi, 2=Hashikalmi, 3=Kalodhan, 4=Ausdhan, 5=Dighabawalia, $6=$ Hanuman jata, 7=Itcrie, 8=V-2, 9=V-3, 10=V-4, 11=Parangi, 12=Sandamioni, 13=Jaymori, 14=Kalohizli, 15= Minikit, 16= Parangi, 17= Raitul, 18=Kuchmuch, 19= Puitraaijang, 20= Boula, 21=Chaina, 22=Saithsail, 23=Sadeyaus, 24=Mallika, 25=Aduballi, 26=Bardhanaus, 27=Kaloaus, 28=Bardhanaus M-74-1, 29=H-171, 30=H-12 , 31=Kadidet.

depends on genetic variability that arises from genetic diversity (Rana and Bhat, 2004). Lack of genetic variability may limit breeding progress and gain from selection. Therefore, knowledge of the genetic diversity of any germplasm collection provides a basis for improvement of crops and development of superior cultivars. This study investigated the allelic diversity existing among the collection of 31 Aus rice genotypes from different districts of Bangladesh using 11 ILP markers.

Consequently, in recent years, introns of genes have been targeted to develop successful intron-length polymorphism (ILP) markers at a genome-wide scale to be utilised for various large-scale genotyping applications in multiple 


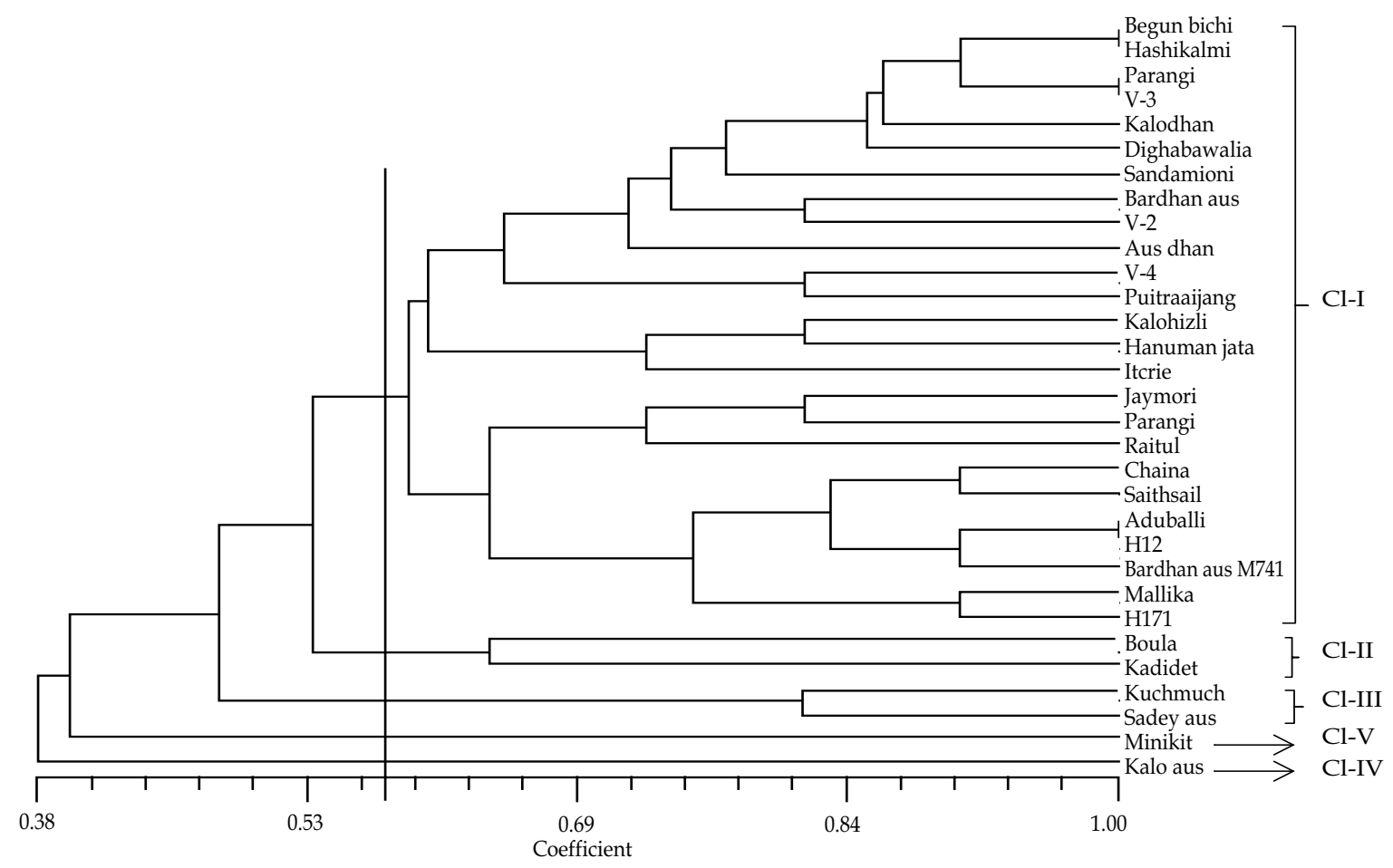

Fig. 2. A UPGMA cluster dendrogram showing the genetic relationships among 31 Aus rice genotypes based on allele detected by 11 ILP markers.

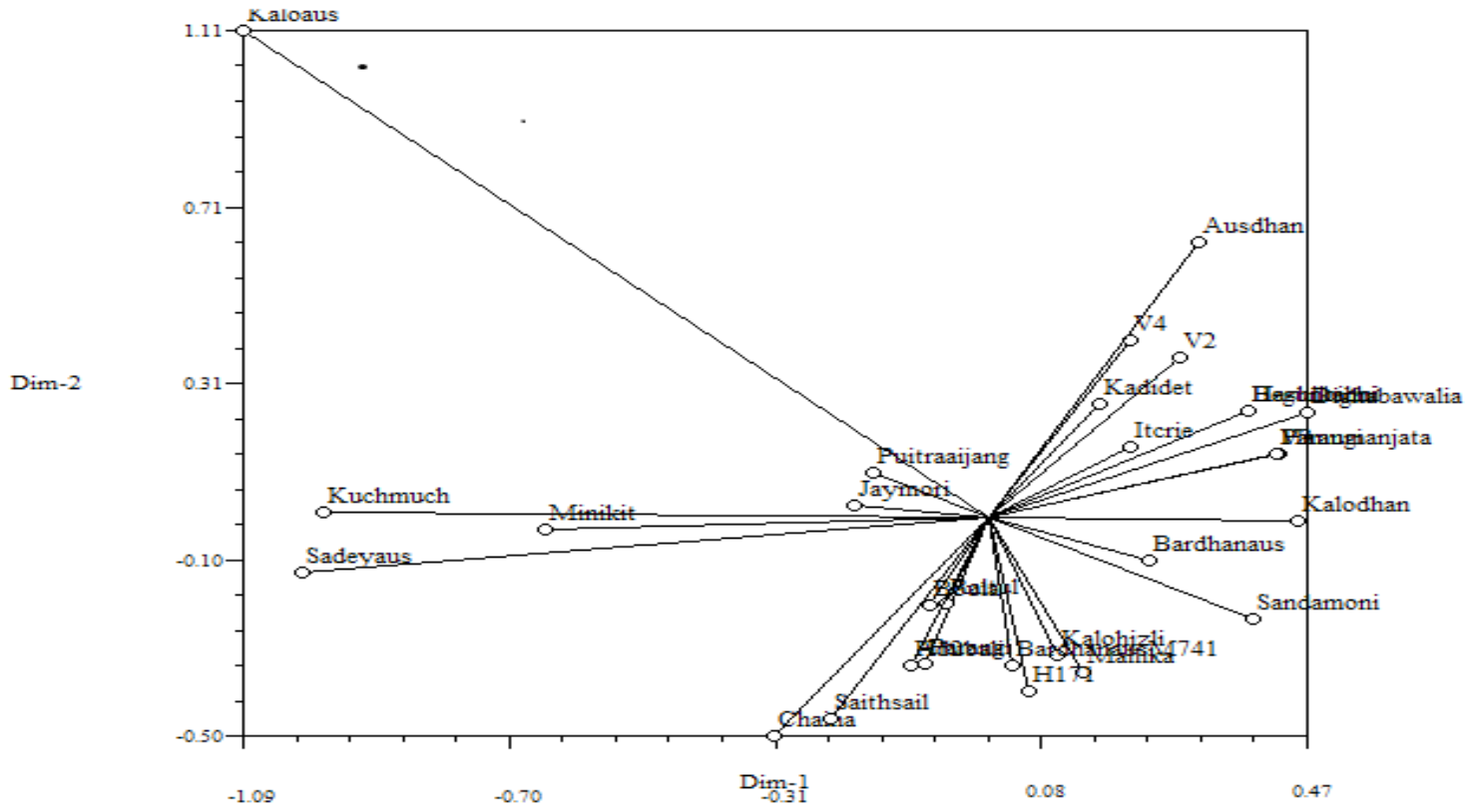

Fig. 3. Two-dimensional view of principal coordinate analysis (PCoA) with 11 ILP markers over 31 Aus rice genotypes. 
major food crop plants, including rice (Zhao et al., 2009). Moreover, ILP is a different type of molecular marker, which has not yet been broadly used in genetic diversity analysis except in a study conducted by Xu et al. (2009), who used ILP primers for indica-japonica differentiation research. In the present study, results showed that 28 alleles with an average of 2.55 alleles per locus were identified by 11 ILP markers. In addition, ILP showed strong subspecies specificity in rice (Wang et al., 2005); it could be very useful for genetic study and breeding in rice.

\section{CONCLUSION}

The results obtained from this study on molecular characterization provided some useful implications for establishment of sovereignty of Bangladeshi rice gene pool. There was a high level of genetic diversity among Aus rice genotypes in this study, suggesting that ILP markers were very effective in the detection of polymorphism in this ecosystem. To broaden the genetic base and improvement of Aus rice, genotypes having the lowest genetic similarities could be selected as parents. Therefore, hybridization should be made between two distant populations. Based on distance matrix, the genotypes Kuchmuch, Kalodhan, Kalohizli, Sandamoni, Kalo aus, Boula, Minikit, Begunbichi, Hanumanjata and Dighibawalia can be selected as parents for further breeding programmes. Parangi and V3, Adubali and H-12, Begunbichi and Hashikalmi had closest distance (0.000) in the distance matrix might have same genetic background. The findings of this study should be useful for varietal identification and could help in providing guidelines for assisting rice breeders in selecting suitable genetically diverse parents for the crossing programme.

\section{ACKNOWLEDGEMENTS}

The authors are grateful to project on 'Collection, characterization and promotion of rice, chilli, cucumber and melon in Bangladesh' supported by AFACI (Asian Food and Agriculture Cooperation Initiative) for providing funds for this research.

\section{REFERENCES}

Bao, J S, H Corke and M Sun. 2006. Analysis of genetic diversity and relationships in waxy rice (Oryza sativa L.) using AFLP and ISSR markers. Genet. Resour. Crop Evol. 53: 323-330.

Cavalli-Sforza, L L and A W F Edwards. 1967. Phylogenetic analysis: models and estimation procedures. Evolution. 21: 550-570.

Chen, H, H He, Y Zou, W Chen, R Yu, X Liu, Y Yang, Y M Gao, J L Xu, L M Fan, Y Li, Z K Li and X W Deng. 2011. Development and application of a set of breeder-friendly SNP markers for genetic analyses and molecular breeding of rice (Oryza sativa L.). Theor.Appl. Genet. 123: 869-879.

Garris, A J, T H Tai, J Coburn, S Kresovich and S McCouch. 2005. Genetic structure and diversity in Oryza sativa L. Genetics. 169: 1631-1638.

Liu, K and S V Muse. 2005. PowerMarker: Integrated analysis environment for genetic marker data. Bioinformatics. 21: 2128-2129.

Londo, J P, Y C Chiang, K H Hung, T Y Chiang and B A Schaal. 2006. Phylogeography of Asian wild rice, Oryza rufipogon, reveals multiple independent domestications of cultivated rice, Oryza sativa. Proc. Natl. Acad. Sci. USA. 103: 9578-9583.

Page, R D. 1996. TreeView: an application to display phylogenetic trees on personal computers. Comput. Mol. Biol. 12: 357-358.

Rabbani, M A, Alwabuchi, Y Murakami, T Suzuki and K Takayanagi. 1998. Genetic diversity in mustard (Brassica juncea L.) germplasm from Pakistan as determined by RAPDs. Euphytica. 103: 235-242.

Ramkumar, G, A K Biswal, K M Mohan, K Sakthivel, A K P Sivaranjanj, C N Neeraja, T Ram, S M Balachandran, R M Sundaram and M S Prasad. 2010. Identifying novel alleles of rice blast resistant genes pikb and pita through allele mining. Int. Rice Res. Notes. 117:185.

Rana, M K and K V Bhat. 2004. A comparison of AFLP and RAPD markers for genetic diversity and cultivar identification in cotton. J. Plant Biochem. Biotech. 13: $19-24$.

Rholf, F. 2002. NTSYS-pc: Numerical Taxonomy and Multivariate Analysis System Version 2.2. New York, USA: Department of Ecology and Evolution, State University of New York. 
Salgotra, R K, B B Gupta, J A Bhat and S Sharma. 2015. Genetic diversity and population structure of basmati rice (Oryza sativa L.) germplasm collected from north western himalayas using trait linked SSR markers. PLOS One, 10 (7): e0131858. doi: 10.1371/ journal.pone.0131858.

Sun, C Q, X K Wang, Z C Li, A Yoshimura and N Iwata. 2001. Comparison of the genetic diversity of common wild rice (Oryza rufipogon Griff.) and cultivated rice (O. sativa L.) using RFLP markers. Theor. Appl. Genet. 102: 157-162.

Thomson, M J, E M Septiningsih, F Suwardjo, T J Santoso, T SSilitonga and S R McCouch. 2007. Genetic diversity analysis of traditional and improved Indonesian rice (Oryza sativa L.) germplasm using microsatellite markers. Theor. Appl. Genet. 114(3): 559-568.

Wang, X S, X Q Zhao, J Zhu and W R Wu. 2005. Genomewide investigation of intron length polymorphisms and their potential as molecular markers in rice (Oryza sativa L.). DNA Res. 12: 417-427.
Xu, X M, K J Liang, S G Zhang, W Sang, Y Y Zhang, X N Wei and P Ke. 2009. Analysis of indica-japonica differentiation in rice parents and derived lines using ILP markers. Sci. Agric. Sin., 42: 3388-3396. (in Chinese with English abstract).

Zhang, P, L Jinquan, L Xiaoling, L Xiangdong, Z Xingjuan and L Yonggen. 2011. Population structure and genetic diversity in a rice core collection (Oryza sativa L.) investigated with SSR markers. PLoSONE. 6(12): 1-13.

Zhao, X Q, L Yang, Y Zheng, Z H Xu and W R Wu. 2009. Subspecies-specific intron length polymorphism markers reveal clear genetic differentiation in common wild rice (Oryza rufipogon L.) in relation to the domestication of cultivated rice (O. sativa L.). J. Genet. Genom. 36: 435-442.

Zheng, K, P K Subudhi, J Domingo, G Magpantay and N Huang. 1995. Rapid DNA isolation for marker assisted selection in rice breeding. Rice Genet. Newsl. 12:255-258. 
